\title{
Forest Mapping of Central America and Mexico with AVHRR Data
}

\author{
Keith B. Lannom \\ USDA, Forest Service, Remote Sensing Applications Center \\ 2222 W. 2300 S. Salt Lake City, UT 84119, U.S.A.
}

\author{
David L. Evans \\ Department of Forestry \\ Box 9681 , Mississippi State \\ MS 39762-9681 (662) 325-2796, U.S.A. \\ E-mail:dle@rs.cfr.msstate.edu
}

\section{William H. Cooke III}

USDA Forest Service, Forest Inventory and Analysis

Box 928, Starkville, MS 39759
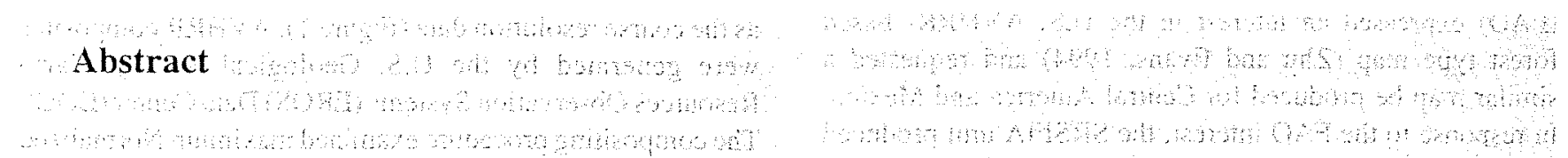

Concerns over changes in global forest resource distributions have prompted a number of stidies to examine and map forest areas at continental scales with various types of satellite data. The work described here details the use of Advanced Very High Resolution Radiometer. (AVHRR) data in concert with Landsat Thematic Mapper (TM) and Systeme Probatoire d'Observation de la Terre (SPOT) imagery to identify and map forest land in Mexico and Central America. A two stage approach was used to accomplish the study objectives. First, a modeling procedure was used to estimate percent forest cover in AVHRR pixels based on enumeration of forest area with Landsat TM and SPOT: data of the same region covered by the AVHRR data. This product was used to subset the original AVHRR data into areas of probable forest lands. The AVHRR spectral data of the subset area was then classified by forest type and the results were compiled to produce the final product. The implications of this work are discissed in the context of global forest monitoring and landscape management.

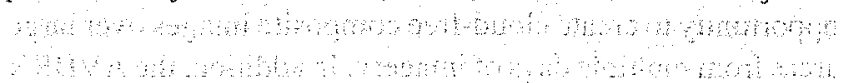

\section{Introduction}

Global forest resources are coming under increased pressure not only for timber production, but also for nontimber values such as watershed protection, wildlife habitat, and maintenance of biodiversity. Improvements in remotely sensed data quality and computer processing have made it possible to develop comprehensive maps of forest resource distributions from satellite data. Such maps, particularly on continental and global scales, are needed to provide scientists and planners with information on the spatial dynamics of forest resources. This information is vital to the long-term management of productive forest lands to provide for future generations.

Localized forest mapping has traditionally been accomplished using aerial photographs and field observations. Regional forest cover maps have been produced through classification of high resolution satellite imagery ever since the first Landsat Multispectral Scanner (MSS) began gathering data in 1972. More recently, data from Landsat Thematic Mapper (TM) sensor and the French satellite, Systeme Probatoire d'Observation de la Terre (SPOT), have been used to map forest cover types. Significant amounts of data are produced by these sensors creating problems for large-area analysis. As the resolution of data increases, so does the amount of computer storage space and time necessary to process the data. Timely mapping of a large area, such as the United States, with TM or SPOT imagery is a complex and expensive undertaking, even with current computer technologies. Advanced Very High Resolution Radiometer (AVHRR) data with a $1-\mathrm{km}$ spatial resolution has been demonstrated as an effective alternative to TM or SPOT for mapping large areas of land cover (Loveland et al., 1991; Loveland et al., 1999) and forest areas (Zhu and Evans, 1994; Stone et al., 1994). 
U.S. Department of Agriculture, Forest Service (USDAFS) scientists at the Southern Research Station, Forest Inventory and Analysis (SRSFIA) unit, Starkville, MS, utilized high-resolution Landsat TM data to model percent forest area within picture elements (pixels) of AVHRR data (Zhu, 1994; Zhu and Evans, 1994). The resulting predicted percent forest area map was used to focus classification efforts on forest areas. The project produced a forest type map which accompanied the 1993 Forest and Rangeland Renewable Resources Planning Act (RPA) Assessment Update program (Powell et all., 1993).

At the time this project was initiated, no forest resource distribution information was available at the project resolution for Mexico and Central America. The FAO was utilizing a technique of statistical sampling and manual interpretation of Landsat data to estimate changes in forest resources on global scales. It was felt that the techniques and satellite technology developed at SRSFIA were appropriate and timely for generation of strategic-level forest cover maps. Officials at the United Nation's Food and Agriculture Organization (FAO) expressed an interest in the U.S. AVHRR- based forest type map (Zhu and Evans, 1994) and requested a similar map be produced for Central America and Mexico. In response to the FAO interest, the SRSFLA unit produced maps depicting the percent forest area and the spatial distribution of forest types for Central America and Mexico

\section{Background}

A significant amount of research indicates that $1-\mathrm{km}$ resolution AVHRR data are suitable for large-area land cover mapping projects. The AVHRR sensor can image a location each day. This high temporal resolution creates the opportunity to create cloud-free composite images over large areas from multiple days of imagery. In addition, the AVHRR visible and near-infrared spectral bands can be used to characterize vegetation vigor and, therefore, are useful for mapping forest areas. The low spatial resolution $(1-\mathrm{km})$, compared to TM $(28.5 \mathrm{~m})$ and SPOT $(20 \mathrm{~m})$, provides a manageable amount of data for global analyses (Brown et al., 1993; Loveland et al., 1991).

A land-cover characteristics database tor the conterminous U.S. was developed from an AVHRR classification and several types of ancillary data (Loveland et al., 1991). This work formed the methodological framework for a project to generate a global database based on similar inputs and methods (Brown et al., 1993). Production of the global database is more recently summarized by Belward et al. (1999), Loveland et al. (1999) and Brown et al. (1999).

Zhu and Evans (1994) reported that "AVHRR data can be used to produce fairly detailed forest-cover maps, provided that sufficient ancillary data are available for identification of spectral classes." Zhu (1994) utilized an innovative technique of using co-registered scenes of high resolution TM data and multitemporal AVHRR data to predict percent Eorest area. These predicted percent forest data were used as ancillary data to the forest type classification procedures for the 1993 RPA Forest Type Group map. The concept of subpixel analysis is not unique to the RPA work. Others have used similar techniques to assess forest cover over limited geographic areas (Cross et al., 1991; Iverson et al., 1989; Ripple, 1994). Procedures similar to those given by Zhu (1994) and Zhu and Evans (1994) were used to create the percent forest area and forest type maps of Central America and Mexico as described in this article. Although the subject project described in this paper predates other global efforts such as described by Belward et al. (1999), it represents a different set of methodologies that have potential utility in global assessments of natural resource distributions.

\section{Methods and Results}

\section{Data acquisition}

The two primary types of data used for this research were low-and high-resolution satellite imagery. AVHRR 10-day composites for April 1992 through March 1993 were utilized as the coarse resolution data (Figure 1). AVHRR composites were generated by the U.S. Geological Survey, Earth Resources Observation Systems (EROS) Data Center (EDC). The compositing procedure examined maximum Normalized Difference Vegetation Index (NDVI) values for multiple scenes to determine areas that were likely to be cloud free for the compositing period. Figure 1 is an example NDVI image from October 1992. Eidenshink (1992) details the procedures necessary to create the 10-day composite images. To get as much cloud-free data as possible for a given area, some of the original EDC composites were combined into monthly, bi-monthly or tri-monthly composites.

The high resolution data sets consisted of $12 \mathrm{TM}$ and 2 SPOT scenes. These data were selected based on two criteria:

- an acquisition date close to 1992 (the AVHRR acquisition year),

- an acquisition date during the dry season (generally between November and March) for relatively cloud-free data.

TM imagery of Mexico was obtained through a cooperative agreement with the USDA Forest Service, the Mexican Secretaría de Agriculturay Recursos Hidráulicos (SARH), Mexican National Forest Inventory unit, and the Universidad Nacional Autonma de México, Instituto de Geografia (UNAM-IG). The TM and SPOT imagery of Central America was purchased through project funds. Ancillary data sources such as cligital elevation data and previous classifications provided guidance during the classification phases of this project. Analysis of all data sets was carried out to accomplish two goals for assessment of the region:

- to determine percent forest area,

- to develop a general forest cover map based on the percent forest area data.

\section{Percent forest area}

The percent forest area map was completed first and used 


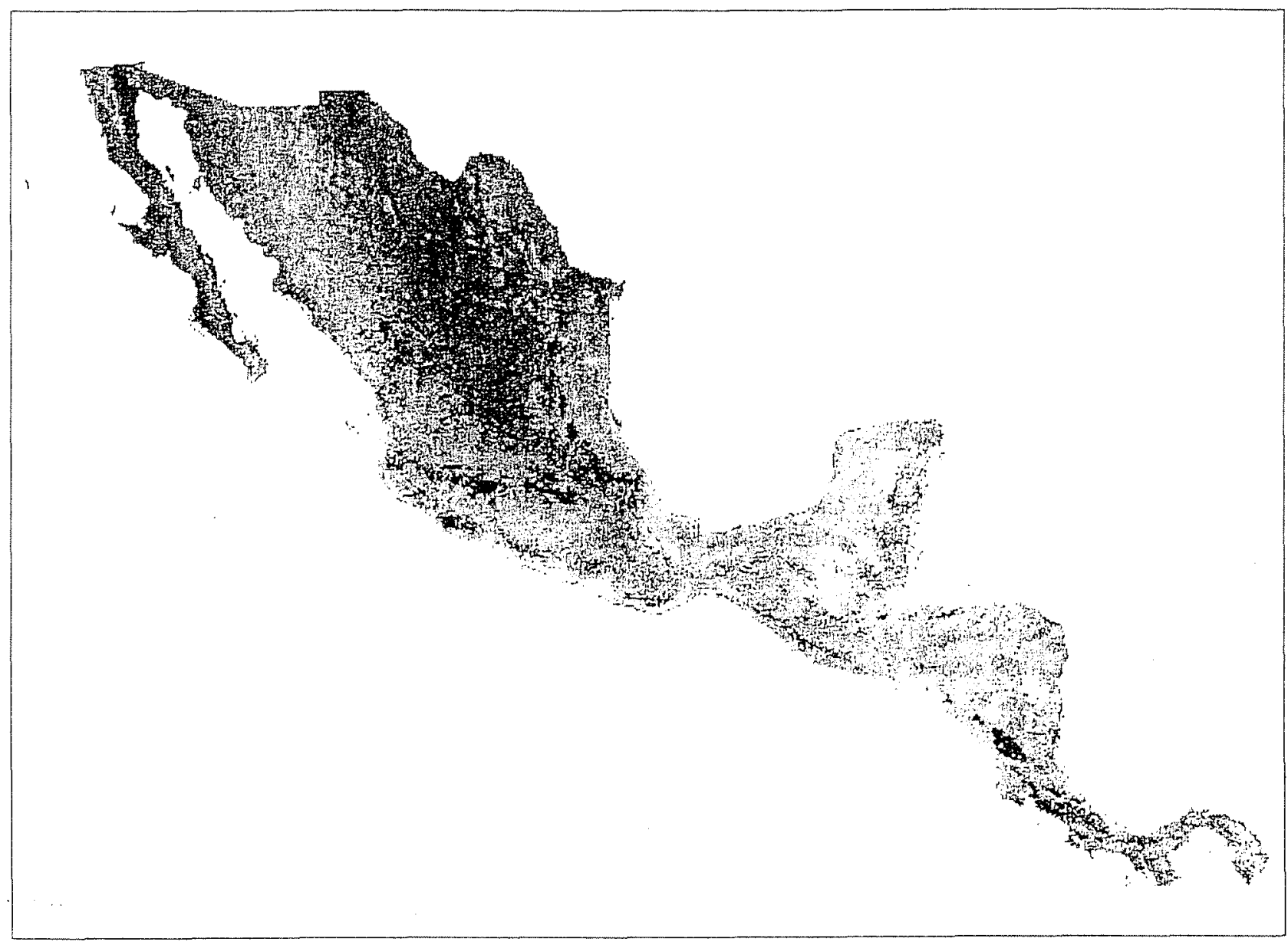

Figure I Example of a 10-day NDVI composite of AVHRR data for Central America and Central America. Light tones indicate high NDVI (vegetation greenness) values while dark tones are low NDVI values. The composite period for these data was mid-October. 1992.

to stratify the entire area as forest or non-forest prior to classification of forest cover types. The methodology that Zhu (1994) used to determine the percent forest area for the U.S. was adopted with minor modification for this project. Subsets of classified high-resolution TM/SPOT images were used to develop regression models to predict percent forest area within low-resolution AVHRR pixels. Models were developed for different regions and a map of percent forest cover was then generated based on the models.

The six steps required to produce the percent forest map were:

- geographic partitioning of the AVHRR data,

- classification of the TM/SPOT scenes,

- identification of regression calibration windows within each geographic partition,

- calculation of the regression equations,

- prediction of percent forest area for individual regions, and

- mosaic the separate regional maps into the final product.

The details of these procedures are given in the following sections.

\section{Geographic partitioning of AVHRR data}

Iverson et al. ( 1989) calibrated AVHRR data with TM data to determine an empirical relationship between AVHRR spectral signatures and forest cover. They determined that areas closer to the calibration center had higher correlation coefficients. This led Zhu (1994) to conclude that multiple regression models were necessary for a large area due to regional physiographic differences. He divided the AVHRR data of the conterminous U.S. into 15 regions to reduce effects of spectral variations between physiographic regions. Loveland et al. (1991) discussed common problems associated with continental-size data sets. Ecological variation (e.g., climate, geological parent material, or elevation) can cause the same vegetation types in separate physiographic regions to appear spectrally distinct. The diversity of the Central American and Mexican landscape required that the AVHRR data be divided into homogeneous physiographic regions prior to analysis. The AVHRR data for Central America and Mexico were partitioned with consideration to the physiography, climate data, and spatial distribution of the available TM/SPOT scenes. At least one TM or SPOT scene was located within each physiographic region.

A mask of each region was used to spatially subset the 
AVHRR composites. Each composite was examined for residual clouds or other data quality problems which could affect the calculation of the regression equations. Composites containing significant cloud cover were either combined to create monthly or multi-month composites. Composites with extreme cloud/haze problems were not used in the ensuing procedures.

\section{TM/SPOT Classifications}

The AVHRR data were partitioned geographically to minimize classification errors caused by environmental variation effects on spectral reflectance. It would be ideal for each TM/SPOT scene to be representative of a different physiographic region. However, the number of quality TM/ SPOT scenes was limited due to prevailing weather patterns over portions of Central America. Some mountainous areas of Costa Rica and Panama have almost continuous cloud cover. As a result, the Central American TM/SPOT scenes were selected based on an even spatial distribution that provided relatively cloud-free data and the best physiographic distribution possible given prevailing weather patterns for the region. In Mexico there was a better distribution of quality TM scenes. Thus, the Mexican TM scenes were chosen to represent the different physiographic regions across the country.

Land cover classes were identified in each TMISPOT scene using unsupervised classification procedures based on the modified $\mathrm{k}$-means clustering algorithm.

The classes were labeled as: conifer, temperate broadleaf, tropical high/medium forest, developed, agriculture, fallow land, and water. Historical aerial photographs, previous classifications of satellite imagery, and aerial video data of Mexico were used as ancillary data to guide the class labeling. The aerial video data were collected during a joint project between SRSFIA and SARH in January 1993 (EggenMcIntosh et al., 1993).

Cristóbal Vasquez of Corporación Hondureña de Desarollo Forestal (COHDEFOR) participated in the classification of the two TM scenes in Honduras as part of a United Nation's Food and Agriculture Organization (UN-FAO) sponsored fellowship. Each TM/SPOT classification was also verified by Dr. Steve Sader of the College of Natural Resources, Forestry and Agriculture, at the University of Maine, or Professor Frank Miller of the College of Forest Resources at Mississippi State University (now retired).

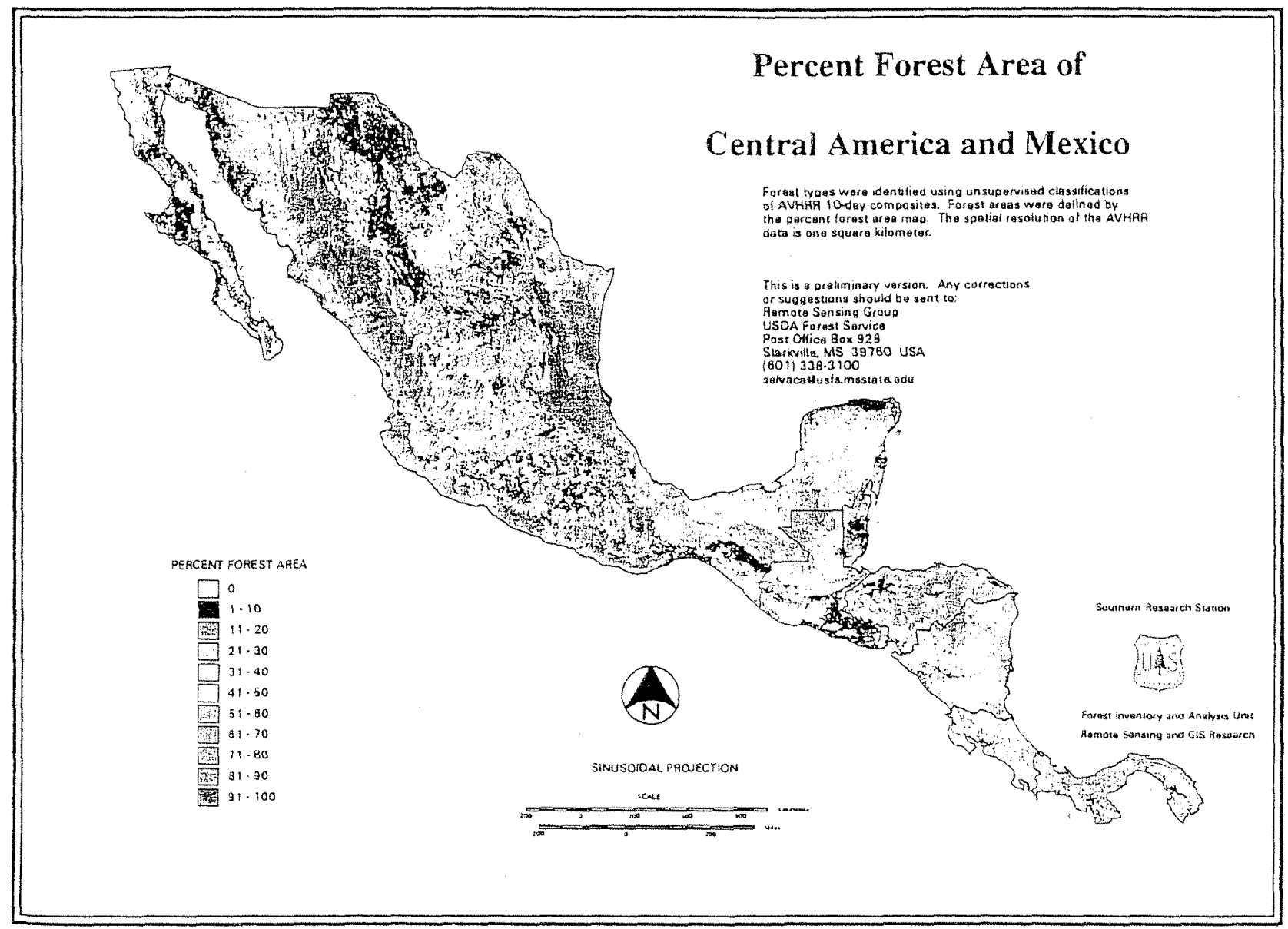

Figure 2 Percent forest cover map of Central America und Nexico based on image data collected in 1992. Large white areals in northern Mexico and along the mountain tanges of southem Mexico and through Central America were either non-forested (c.g., large lakes) or were not modeled due to lack of data (clouds). 


\section{Calibration Windows}

The next step was to identify a calibration window for each physiographic region. Each calibration window covered the same area on both the low- (AVHRR) and high-(TM/ SPOT) resolution data sets. The data within the calibration windows were used to calculate the regression equations. The TM classifications were recoded into forest and nonforest categories then resampled from the original $30 \times 30 \mathrm{~m}$ resolution to $25 \times 25 \mathrm{~m}$ pixels to ensure that they would nest spatially within the corresponding AVHRR data $25 \times 25 \mathrm{~m}$ TM pixels provide an even subdivision of the $1 \mathrm{~km}$ AVHRR pixels). Nearest neighbor resampling was used to preserve the integrity of the categorical information of the Landsat classification. The $20 \times 20 \mathrm{~m}$ pixels of the SPOT data did not require resampling.

Initially, 30-by-30 pixel AVHRR pixel calibration windows were selected. These windows covered 1200-by1200 pixel windows in the resampled TM data. The size of calibration windows differed in some regions because some of the TM/SPOT scenes contained areas that could not be used for the modeling procedures (e.g., clouds or large water bodies). In these cases, the calibration window size was dictated by the usable area in the TM/SPOT data. An alternate method of calibration window extraction involved choosing 4 smaller windows in regions where there was not a large, contiguous block of TM/SPOT pixels suitable for extraction.

\section{Regression equations development}

The TM/SPOT forest and non-forest classification data within the calibration windows were converted to a percent forest area value per square kilometer basis. These percent forest area values were matched with the geographically corresponding AVHRR values for the regression analysis. AVHRR NDVI values were used for the regression procedures in addition to the five bands of AVHRR data.

Step-wise regression procedures were then used to compare various AVHRR band combinations to the $1-\mathrm{km}$ TMISPOT percent forest area data. The resulting regression equations were evaluated by coefficients of determination $\left(R^{2}\right)$. The equation with the highest coefficient of determination was selected to predict percent forest area for the entire physiographic region (Appendix A).

\section{Modelling Percent Forest Area}

Multitemporal data sets for each region were created from the AVHRR bands designated in the final regression equations. The regression parameters were applied to each multitemporal data set to calculate a percent torest area value for each $1-\mathrm{km}$ pixel of each physiographic region. The resulting model outputs were combined to produce a single percent forest map for all Central America and Mexico (Figure 2). To assess the quality of the percent forest area models, the results obtained from the modeling procedure are presented in Table 1 . The highest $R^{2}$ was in Western Honduras while the lowest was in Chetumal. The average Rfor all regions was 0.6355
Table 1 Coefficients of determination by physiographic region.

\begin{tabular}{ll}
\hline \multicolumn{1}{c}{ Region } & $\mathrm{R}^{2}$ \\
\hline Costa Rica & 0.5974 \\
Guatemala & 0.6610 \\
Central Honduras & 0.6427 \\
Western Honduras & 0.8202 \\
Nicaragua & 0.4196 \\
Panama & 0.7274 \\
Chetumal & 0.4013 \\
Chiapas & 0.6801 \\
Chihuahua & 0.7541 \\
Jalisco & 0.6491 \\
Mexico City & 0.6625 \\
Oaxaca & 0.5614 \\
Sinaloa & 0.5262 \\
Tamaulipas & 0.7934 \\
\hline
\end{tabular}

\section{Forest type classification}

The regional multitemporal AVHRR data sets created for the percent forest modeling procedures were also used to classify the forest types of Central America and Mexico. The percent forest area map served as the main source of ancillary data for the forest type classifications. Non-forest areas were masked using the percent forest area data in order to focus classification efforts on the primary objective of mapping forest types.

The threshold between forest and non-forest was determined for each region based on comparisons of the percent cover map to existing vegetation maps and the unclassified AVHRR data. Threshold values ranged from 25 to 35 percent. Areas which fell below the percent forest threshold level were considered non-forest but are not necessarily without woody vegetation. For example, portions of the Baja Peninsula have very low percent forest area values but some species of woody shrubs may inhabit these areas.

Non-forest areas were masked from the regional multitemporal data sets and the remaining data were classified using an iterative process of unsupervised classification methods. Each physiographic region was analyzed independently. Class labeling was guided by vegetation maps, elevation data, Landsat image prints, and previous classifications/interpretations of TM/SPOT images. Seven forest cover classes were identified: conifer, conifer/temperate broadleaf, conifer/tropical broadleaf, temperate broadleaf, tropical high/medium forest (jungle), tropical low forest (jungle), and mangrove (Figure 3). The remaining cluster classes were grouped into three classes: non-forest, water, and cloud. Some residual clouds remained in the multitemporal data sets.

The classes for tropical forest (high/medium versus low jungle) were suggested by the cooperators from the countries with direct involvement in the project. These correspond to the classes that are used for assessment of forest cover and are directly related to the information that they used to 
compile resource data for FAO. These classes are based on structural variations in forest canopy that are usually associated with climatologic/hydrologic regimes. The high/ medium jungle corresponds to what many consider to be primarily wet tropical forest while the low jungle primarily dominates lower/drier site conditions. This classification system is somewhat in contrast to what some use for classification based on disturbance regime (primary versus secondary forest). The differences in forest definition and classification became apparent with examination of the Mexico/Central America product as compared to the product described by Loveland et al., (1999).

\section{Type map validation}

A comparative assessmerit was made between the forest map of this project and one obtained from the global project documented by Loveland et al., (1999). Data from the latter was obtained from the worldwide web site http:// edcwww.cr.usgs.gov/landdaac/glcc/glcc.html and registered to the Central America classification. It should be noted that the global product used AVHRR NDVI data from the same time frame (1992-93) as the Central America work.

A cross-reference scheme was devised to equate the classification systems from the two different projects (Table 2). It was realized that some latitude would have to be allowed in making the comparisons due to the differences in forest definition that existed between the two projects. The product for Mexico and Central America contained information targeted at the regional scale classification that included a distinction between tropical and temperate forests while the other project did not make a similar distinction. Assumptions as to equivalent types had to depend in-part on knowledge of local physiographic/climate regimes for any given area. For example, the global deciduous broadleaf forest class could be considered as either the temperate broadleaf or low jungle classes (both can be deciduous at certain times of the year) depending on the location of the comparison sites.

Sample sites were chosen in a stratified random allocation procedure that resulted in 175 locations being selected for examination. The results of the comparisons are given in Table 3. The assumption made for this table is that the global classes redesignated to the Central America classification system served as the reference data. Agreement is given using conditions for determination outlined by Congalton and Green ( 1999).

\section{Discussion}

A significant amount of effort was devoted to

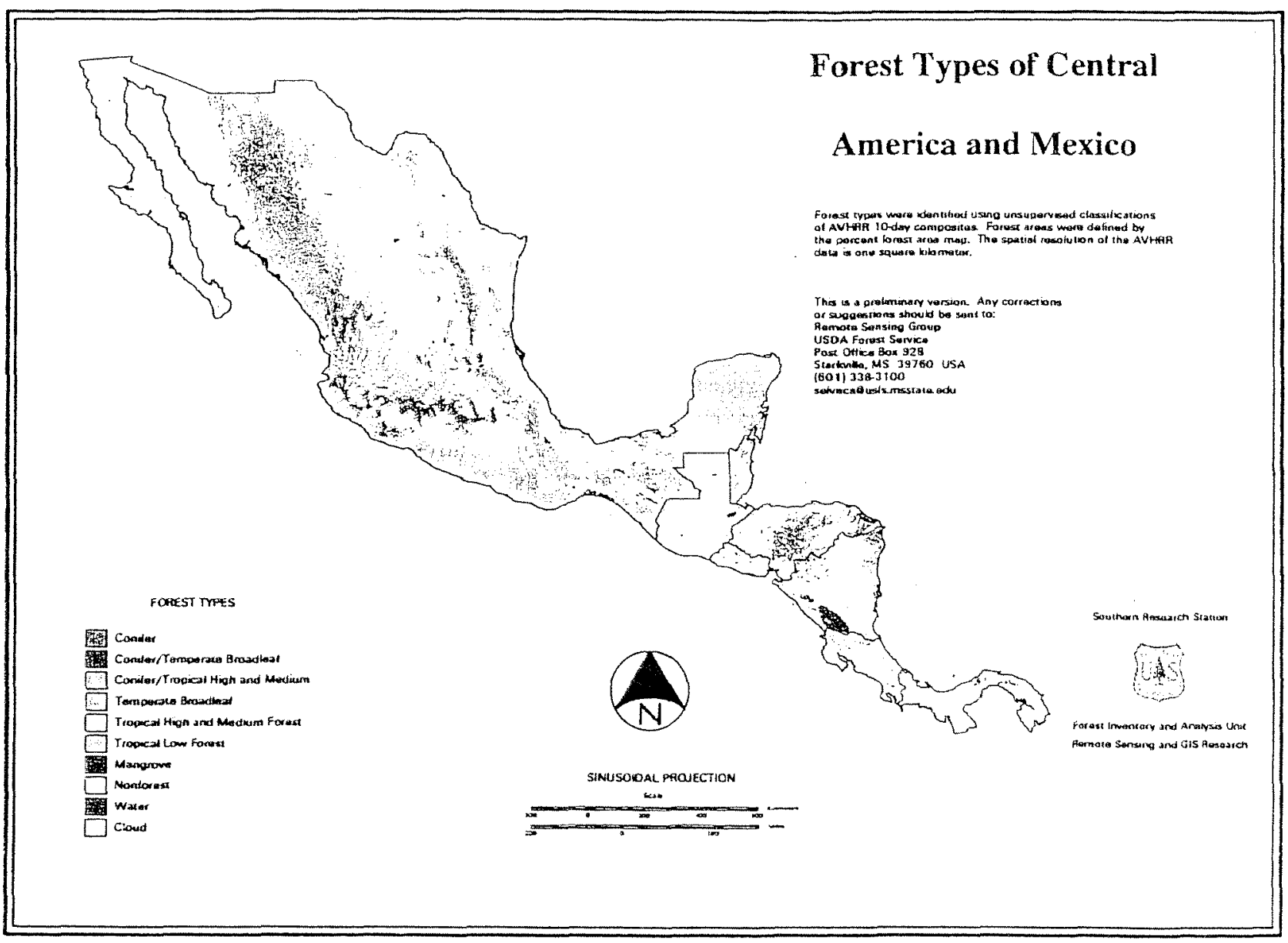

Figure 3 Forest cover type map of Central America and Central America based on inage data collected in 1992 
Table 2 USGS global land use/land cover classes and Mexico/Central America classification equivalents.

\begin{tabular}{ll}
\hline USGS Global Class & Mexico/Central America Class \\
\hline Urban and Built-up Land & Non-forest \\
Dryland Cropland and Pasture & Non-forest \\
Irrigated Cropland and Pasture & Non-forest \\
Mixed Dryland/lrigated Cropland & Non-forest \\
and Pasture & \\
Cropland/Grassland Mosaic & Non-forest \\
Cropland/Woodland Mosaic & Non-forest \\
Grassland & Non-forest \\
Shrubland & Non-forest \\
Mixed Shrubland/Grassland & Non-forest \\
Savanna & Non-forest \\
Deciduous Broadleaf Forest & Temperate Broadleaf Forest or \\
Deciduous Needleleaf Forest & Low Jungle \\
Evergreen Broadleaf Forest & (no equivalent) \\
& Temperate Broadleaf Forest, \\
& Tropical High/Medium Forest, \\
Barren or Sparsely Vegetated & Tropical Low Forest, or \\
\hline
\end{tabular}

development of AVHRR data sets that were reasonably free of cloud cover. In general, for this region of the world, cloud-free imagery over large regions is difficult if not impossible to obtain. The combination of tropical climate and mountainous terrain virtually insures that cloud cover will persist over higher elevations of the landscape. Some of the AVHRR 10-day composites provided cloud-free coverage of large areas but none of the composites were completely cloud-free for the entire project area. Even combined monthly or multi-monthly composites exhibited cloud cover problems that could not be fully resolved. It was not surprising that the majority contribution to the final regression equations came from the winter month composites (January/February). Reduced tropical weather activity provided for more cloud free AVHRR data than in the summer months.

The validation comparison between the two data sets produced some interesting but not necessarily surprising results. One notable difference between the products involved the conifer class. Although there were 17 sites identified in the reference (global) data as conifer, only one was identified as the same in the Central America classification. Of 59 non-forest reference sites, only 20 were identified as non-forest in the Central America product. In the first case, conifer in the reference data was frequently identified as temperate broadleaf in the Central
Tabie 3 Vatidation compiled by comparison of the Mexico / Central America classification to the global land characterization map product. (no sices were selected in Mangrove or water due to small size of the classes in the study urea).

\begin{tabular}{|c|c|c|c|c|c|}
\hline Class Name & $\begin{array}{c}\text { Reference } \\
\text { Sites }\end{array}$ & $\begin{array}{c}\text { Classified } \\
\text { Sites }\end{array}$ & $\begin{array}{l}\text { Number } \\
\text { Correct }\end{array}$ & $\begin{array}{l}\text { Producer } \\
\text { Agreement }\end{array}$ & $\begin{array}{c}\text { User } \\
\text { Agreement }\end{array}$ \\
\hline Conifer & 17 & 22 & 1 & $5.9 \%$ & $4.6 \%$ \\
\hline $\begin{array}{l}\text { Conifer/ } \\
\text { Temperate }\end{array}$ & 24 & 25 & 15 & 62.5 & 60.0 \\
\hline $\begin{array}{l}\text { Conifer/ } \\
\text { Tropical }\end{array}$ & 2 & 3 & 0 & 0.0 & 0.0 \\
\hline $\begin{array}{l}\text { Temp. } \\
\text { Broadleaf }\end{array}$ & 6 & 25 & 4 & 66.7 & 16.0 \\
\hline $\begin{array}{l}\text { Tropical } \\
\text { High/Med. }\end{array}$ & 45 & 50 & 40 & 88.9 & 80.0 \\
\hline Tropical Low & 22 & 25 & 19 & 86.4 & 76.0 \\
\hline Non-forest & $\underline{59}$ & 25 & $\underline{20}$ & 33.9 & 80.0 \\
\hline Totals & 175 & 175 & 99 & & \\
\hline
\end{tabular}

Overall agreement is $56.6 \%$

Forest / non-forest classification agreement is $74.9 \%$

America classification. One possible explanation for this is that the temperate broadleaf trees (primarily found in Mexico) are not always deciduous and therefore could have been confused with the evergreen conifer class of the global database product. In the non-forest reference class, 16 of the differing sites were identified as conifer in the Central America product. Upon closer examination, it was noted that a number of these sites occurred in areas of Honduras that are in conifers with low crown closure. This was confirmed by the country cooperator and with aerial photography provided of the region. Low crown closure in pine stands could have been interpreted as nonforest (grass and herbaceous reflectance) in the global product. The other forest classes, with the exception of temperate broadleaf, exhibited fairly good agreements. Such comparisons taken in concert with respectable regression results indicated earlier, although not entirely conclusive as to validity of the products, hold the assumption that an accumulation of supporting evidence of correct classification provides credibility in the final result (Brown, et al. 1999).

Tropical forest assessments through remote sensing techniques have become an important component in the broader topic of global climate change research. We no longer have to speculate, based on limited sampling techniques, how global forest resources are changing. Products such as these provide full enumeration of the entire aerial extent of the resource. Recent studies, including this one, have demonstrated that, through various analysis innovations, it is possible to provide usetul products that depict the distribution of tropical forests.

There are important implications in terms of general land 
management policy that spring from efforts such as this. These types of products can provide countries with current information on the distribution of their natural resources. Global forest conditions can be monitored to provide timely data necessary for biodiversity assessments and resource allocations. In addition, comparisons of these products over time give planners the opportunity to make decisions on future resource use based on past changes in the spatial distribution of forest lands. These change detection data used in combination with other geographically-based knowledge (i.e., populations, transportation, etc.) could also be used to predict future conditions and distributions of forest resources; for example, the changes in the Amazon tropical rain forest due to construction of new roads.

The demands on our global resources are changing constantly. Wise allocation of natural resources depends on accurate and timely information. These data sets provide a synoptic view of forest conditions of Central America and Mexico.

These procedures could be repeated in other parts of the world to create a global percent forest area data set.

\section{References}

Belward, A.S., Estes, J.E., and Kline, K.D. 1999. The IGBP-DIS global $1-\mathrm{km}$ data set DISCover: a project review. Photogrammetric Engineering and Remote Sensing. 65(9): 1013- 1020.

Brown, J.F., Loveland, T.R., Merchant, J.W., Reed, B.C., and Ohlen, D.O., 1993. Using multisource data in global land-cover characterization: concepts, requirements, and methods. Photogrammetric Engineering and Remote Sensing. 59(6):997987

Brown, J.F., Loveland, T.R., Ohlen, D.O., and Zhu, Z. 1999. The global land-cover characteristics database: the users' perspective. Photogrammetric Engineering and Remote Sensing. 65(9):10691074.

Congalton, R.G., Green, K. 1999. Assessing the accuracy of remotely sensed data: principals and practices. Lewis Publishers, New York. $137 \mathrm{p}$.

Cross, A.M., Sette, J.J., Drake, N.A., and Paivinen, R.T.M. 1991. Subpixel measurement of tropical forest cover using AVHRR data. International Jounral of Remote Sensing. 12(5): 1119-1129.
Eggen-McIntosh, S., Jacobs, D.M., and Flores, A., 1993. Acquisition of airborne videography of Mexico for verification of FAO forest resources assessment Landsat interpretations. In: Proceedings of the 14th Biennial Workshop on Color Aerial Photography and Videography for Resource Monitoring: 1993 May 25-29; 29; Logan, UT. Bethesa, MD: American Society for Photogrammetry and Remote Sensing. pp. 135-144.

Eidenshink, J.C., 1992. The 1990 conterminous U.S. AVHRR data set. Phorogrammetric Engineering and Remote Sensing. 58(6):809-813.

Iverson, L.R., Cook, E.A., and Graham, R.L., 1989. A technique for extrapolating and validating forest cover across large regions: calibrating AVHRR data with TM data. International Journal of Remote Sensing. 10(11):1805-1812.

Loveland, T.R, Merchant, J.W., Ohlen, D.O., and Brown, J.F., 1991. Development of a land cover characteristics database for the conterminous U.S. Photogrammetric Engineering and Remote Sensing. 57(11): 1453-1463.

Loveland, T.R., Zhu, Z., Ohlen, D.O., Brown, J.F., Reed, B.C., and Yang, L. 1999. An analysis of the IGBP global land-cover characterization process. Photogrammetric Engineering and Remote Sensing. 65(9):1021-1032

Powell, D.S., Faulkner, J.L., Darr, D.R., Zhu, Z., and MacCleery, D.W., 1993. Forest resources of the United States, 1992. Gen. Tech. Rep RM-234. Fort Collins, CO: U.S. Department of Agriculture, Forest Service, Rocky Mountain Forest and Range Experiment Station. 132 p. + map. [Revised June 1994]

Ripple, W.J. 1994. Determining coniferous forest cover and forest fragmentation with NOAA-9 Advanced Very High Resolution Radiometer data. Photogrammetric Engineering and Remote Sensing. 60(5):533-540.

Stone, T.A., Schlesinger, P., Houghton, R.A., and Woodwell, G.M. 1994. A map of the vegetation of South America based on satellite imagery. Photogrammetric Engineering and Remote Sensing. $60(5): 541-551$.

Zhu, Z., 1994. Forest density mapping in the lower 48 states: a regression procedure. Res. Pap. SO-280. New Orleans, LA: U.S. Department of Agriculture, Forest Service, Southern Forest Experiment Station. 11 p.

Zhu, Z. and Evans, D. L., 1994. U.S. Forest types and predicted percent forest cover from AVHRR data. Photogrammetric Engineering and Remote Sensing. 60(5):525531. 


\section{Appendix A}

Regression models used in the percent forest area modeling procedures.

$\begin{array}{lc}\text { Region } & \mathrm{R}^{2} \\ \text { Chihuahua, } & 0.86 \\ \text { Mexico } & \\ \text { Sinaloa, } & 0.70 \\ \text { Mexico } & \\ \text { Tamaulipas, } & 0.69 \\ \text { Mexico } & \\ \text { Mexico City, } & 0.78 \\ \text { Mexico } & \\ \text { Jalisco, } & \\ \text { Mexico } & \\ \text { Oaxaca, } & 0.81 \\ \text { Mexico } & \\ \text { Chiapas, } & \\ \text { Mexico } & 0.81\end{array}$

Model $^{\dagger}$

$111.5928+(1.4874) \mathrm{ja}[6](1.8466) \mathrm{ja}[5](0.2103) \mathrm{ja}[2]+$ $(1.5968) \mathrm{ja}[3]+(0.5858) \mathrm{sp}[6](0.7020) \mathrm{sp}[4]$

$+(0.6431) \mathrm{sp}[5]+(0.0093)$ no[3]+(0.7062)no[6]

$180.4490+(0.7284)$ ocnode $[6]+(0.6311) \mathrm{jn}[6]+(3.9456)$

ja3 [4] (0.4960)fe 1 [1] (2.009l)fe $1[4]+(1.5329) \mathrm{fe} 1[3]$

(2.9735)ja3([5] (0.3642)ja3[1] (0.4368)fe[3!

$504.1144+(3.6110)$ jafe[6] (0.8196)jn2[5]-

$(0.4653)$ jafe[2]+(0.9249)jafe[1](0.1952)apmyjn[5]+

(0.0710)ocno[2] (0.6503)ocno[6] (0.1662)ocno[5]

[2.1428+(1.7572)fe[6] (0.1229)apmyjn[2]

$+(0.0954)$ ocnode[2] $(0.2614)$ ocnode[4]

$0.73490 .7810(0.2605) \mathrm{myl}[3](0.3119)$ fe $3[1](0.1952)$

fel[3]+(0.5533)mr[6] $(0.1741) \mathrm{jal}[1](0.3043) \mathrm{myl}[6]$

(0.1744)fel[1] (0.3398)fel[6]

$57.1313+(2.5899) \mathrm{fe}[6]+(0.0595)$ ocnode[2](1.1407)

jafemr[6] (0.1218)apmyjn[2] (0.1243)apmyjn[5] (0.1213)

jafemr $[1]+(0.1177) \mathrm{fe}[1]$

$278.9404+(0.0984) \mathrm{fe} 2[2](0.3800) \mathrm{fe} 2[3]+(0.9178)$

fe2[6](0.0259)apmyjn[3]+(0.0328)apmyjn[4]+(0.0249)

ocnode[3](0.1370)ocnode[4]-(0.0923)

ocnode[1]

\begin{tabular}{|c|c|c|}
\hline $\begin{array}{l}\text { Chetumal, } \\
\text { Mexico }\end{array}$ & 0.51 & $\begin{array}{l}3274.7559+(6.6092) \mathrm{fe} 2[4]+(4.1919) \mathrm{fe} 2[1](1.2108) \\
\text { ocnode[6]+(0.3243)jlausp[5](0.1561)ja [2]+(0.80)jat[[4]- } \\
(6.8644) \mathrm{fe} 2[5]+(3.6268) \mathrm{fe}[5]+(0.4557) \mathrm{fe}[2](1.8623) \mathrm{fe}[3] \\
-(1.6086) \mathrm{fe} 2[2]+(8.5884) \mathrm{fe} 2[6]\end{array}$ \\
\hline Guatemala & 0.73 & $\begin{array}{l}163.8954+(0.1511) \mathrm{fe} 2[2]+(0.2751) \text { ocnode }[6]+(0.0909) \\
\text { ocnode[3]+(0.4497)jafe[6]-(0.2743)fe2[1] }\end{array}$ \\
\hline $\begin{array}{l}\text { Western } \\
\text { Honduras }\end{array}$ & 0.72 & $\begin{array}{l}677.1533(1.5256) \mathrm{ja} 1[4]+(1.1008) \mathrm{ja} 1[5]+(0.1361) \\
\text { jafemr[2] }(0.6592) \mathrm{fe} 2[4](0.6867) \mathrm{jal}[6](0.5666) \mathrm{jafemr}[1] \\
(0.0757) \text { jal } 1[2](0.4656) \text { ocnode[6]+(0.5493)fe2[5] }\end{array}$ \\
\hline $\begin{array}{l}\text { Central } \\
\text { Honduras }\end{array}$ & 0.59 & $\begin{array}{l}235.4841(0.1379) \text { jlausp[2] }(0.1844) \operatorname{mr}[1](0.5941) \\
\text { ocnode[3]+(0.5391)ocnode[5] }(0.1478) \text { jafe[1] }(0.9123) \\
\text { jlausp[6]+(0.5210)jafe[6] }\end{array}$ \\
\hline Nicaragua & 0.72 & $\begin{array}{l}33.4864+(1.3917) \mathrm{mr}[1]+(2.3104) \text { jafe[6]-(1.7224) } \\
\text { ocnode[3]+(0.6864)ocnode[5]+(0.3140)apmyjn[6]+ } \\
(3.2938) \mathrm{mr}[6]-(0.5954) \mathrm{mr}[2]-(0.0872) \text { apmyjn[3]-(0.0451) } \\
\text { apmyjn[2] }\end{array}$ \\
\hline Costa Rica & 0.73 & $\begin{array}{l}117.5941(0.1789) \text { jafemr[3]+(2.8843)jafemr[6] }(0.4532) \\
\text { ocnode[3] }(0.5087) \text { ocnode[5]+(0.7180)ocnode }[4]\end{array}$ \\
\hline Panama & 0.67 & $\begin{array}{l}587.9572+(2.4824) \operatorname{re}[6](0.8151) \text { ocnode }[3]+(0.7727) \\
\quad \operatorname{mr}[6](0.4245) \text { jatemr[3] }(0.1390) \operatorname{mr}[4]+(0.0677) \operatorname{mr}[2]\end{array}$ \\
\hline
\end{tabular}

Refers to the general location of each geographic region.

AVHRR channels in the equations are identified by their month, composite period, and spectrat channel number [1-5] or NDVI channel [6]. There are three composite periods for each month. For example, jn 16] would be the June $1-10$ composite, channel 6 (NDVI). Some AVHRR images are monthly composites (e.g., ap is a composite of ap I, ap2, and ap3). Multi-month composites are indicated by combined abbreviations (e.g., apmyjn for April, May, June). 